\title{
Geodynamic Monitoring of Development of a Karst on the Basis of Georadar Sounding
}

\author{
Oleg R. Kuzichkin ${ }^{1}$, Elena S. Mikhaleva ${ }^{1}$, Nikolay V. Dorofeev ${ }^{2}$, Roman V. Romanov ${ }^{2}$ \\ ${ }^{1}$ Belgorod National Research University, 85 Pobedy st., Belgorod 308015, 1155464@bsu.edu.ru \\ ${ }^{2}$ Vladimir State University named after A. G. and N. G. Stoletovs, 23 Orlovskaya st., Murom 602264, itpu@mivlgu.ru
}

\begin{abstract}
The questions of practical application of georadar sounding for the detailed studying of development of a karst were considered in the article. The importance of the problem being solved for the planning of construction and further operation of industrial facilities in karst limestone areas is emphasized. In the last case, the geodynamic control of karst zones is necessary, as operation of objects in these zones is economic. The analysis of the interferences influencing the results of geodynamic control of a karst with use of georadar shooting is carried out. The model of the effect of temperature variations in the geological environment is made, which are the most essential reason of occurrence of interference. It was found that, in accordance with experimental studies with longer exposure to temperature penetration depth is limited to ten meters, and the lag time is one month in average for one meter. The temperature correction algorithm was proposed and tested, which allows to increase the reliability of registering geodynamics of karst processes with the use of georadar sensing.
\end{abstract}

Keywords-georadar sounding, karst, geodynamic control, natural-technical systems, non-destructive testing

\section{INTRODUCTION}

In practice, for solving the problems of protection of natural and technogenic objects from the possible consequences of catastrophes, as well as monitoring of the carrying capacity of overlying and underlying soil during the operation of industrial facilities in karst areas, it is advisable to use the monitoring systems of geodynamic control [1-3]. They allow to carry out the relative assessment of geomechanical changes happening due to development of karst processes and to carry out the prognosis evaluation of the possibility of technogenic catastrophes on the basis of algorithms of informational data processing of geodynamic monitoring.

In this case, we understand karst geodynamic objects as objects of geodynamic monitoring: generally it is a geological section, and in particular, these are nearsurface and deep inhomogeneities of karst origin. In [4] the basic provisions and general requirements for the composition and content of the work of monitoring the state of the geological environment are defined; for exogenous processes the controlled parameters and the period of carrying out the observations are stated, as well as conditions of prognosis evaluation. At the same time, the main direction of monitoring works is the monitoring procedure of a trend component of geodynamic parameters. However, as the recently conducted researches showed, the cyclic variations in most cases are defining when forming prerequisites of accidents at technogenic objects. As a result, a defining feature of the geodynamic control is the definition and independent control of both the trend component and periodic changes in the environment, caused by cyclical factors [5].

Use of a method of georadar sensing for geodynamic monitoring of karst processes allows to determine a nearsurface karst geodynamic object and its trend changes in geological environment [6]. However, in case of in-depth research it is necessary to use indirect signs of karst processes. In this case, the main problem of control is the presence of periodic variations at georadar sensing determined by impacts of climate-related factors [7]. It becomes more and more actual because of possibilities of latent qualitative changes in local climate dynamics revealed last years, and such changes introduce essential corrections in economic estimations of climate-related damages [8].

In particular, variable patterns of space heterogeneities of annual warming-cooling cycles [9] and abrupt temperature shifts within interseasonal hysteresis regularities [10] are typical for the Nizhny Novgorod region, where our experimental tests are made. From the practical viewpoint, it means the necessity to pay more attention to influence of local temperature peculiarities on weather-dependent technologies. So, the aim of this work is to study the effect of the observed temperature interference on the results of registration of karst processes geodynamics and the development of robust algorithms for determining of geodynamic changes on the basis of applicable control patterns.

\section{MODEL OF INFLUENCE OF TEMPERATURE ON THE Results of GEORADAR MONITORING OF PERIODIC VARIATIONS OF KARST ANOMALIES}

At georadar monitoring of periodic variations of karst anomalies, it is necessary to consider the dependence of the obtained data on temperature factors. The temperature interference in the analysis of time series of georadar data is the consequence of the principles of operation of a georadar [11]. For georadar researches in a wide 
frequency range the key informative parameter is the dielectric dispersion, that is its dependence on frequency of the applied electromagnetic field. If we consider the strong dependence of dielectric permeability on temperature, then it is a very composite dependence. Therefore, the main sign for determining of karst anomalies in the thicknesses of simulated or natural layers is their contrast on dielectric permeability. Therefore for the solution of engineering tasks, including monitoring researches, it is necessary to establish connection between an inductivity and the required characteristics of the studied environment - water saturation, lithology, aggregate state, etc., that can be made in each case by means of application of parametrical models [12].

It is known that dielectric permeability of the environment is defined by water saturation, which defines its strong temperature dependence [13]. According to the experimental data, the dependence of dielectric permeability of water on temperature is well described by the equation:

$$
\varepsilon_{n}=\varepsilon_{0}-\alpha_{\varepsilon} T
$$

where $\alpha_{\varepsilon}$ - coefficient of dependence of an inductivity on temperature.

Fig. 1 shows the dependence of the dielectric constant on the frequency of forest soil at different temperatures.

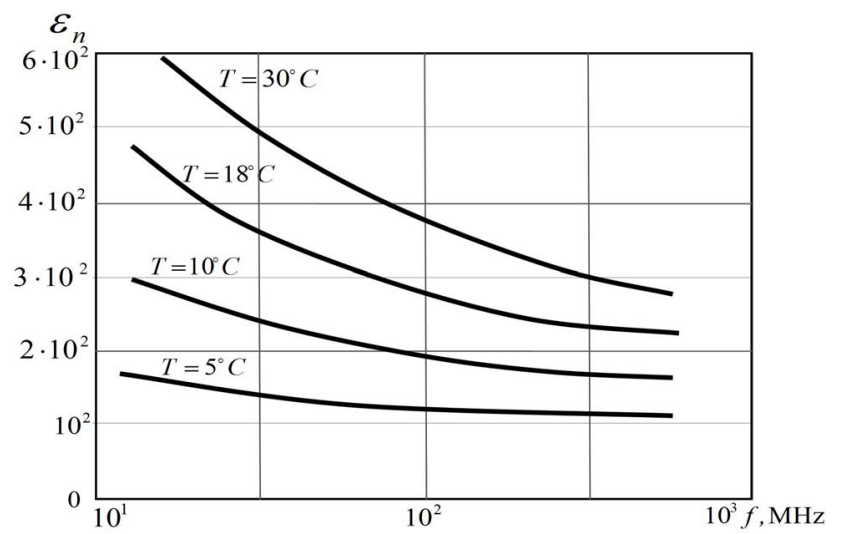

Figure 1. The dependence of the dielectric permittivity of the forest soil frequency

Dependences of electromagnetic parameters of rocks on water saturation and the mineralization of water solutions are discussed in detail in $[14,15]$ and can be used to create algorithms of processing in automated control systems of geodynamic objects. Accordingly, the level of thermal interference in the registration georadar sensing data is determined by the temperature dependence of the electrical parameters of the geological section and thus the depth of penetration of thermal waves in the environment.

As it is seen from the Fig. 2, at longer influence, the depth of penetration of temperature is limited to ten meters, and the delay time averages to one month for one meter. Seasonal (annual) fluctuations cause the changes of temperatures at depths up to $20-40 \mathrm{~m}$. At such depths, the heat transfer is carried out generally due to molecular heat conductivity, and also movement of underground waters.

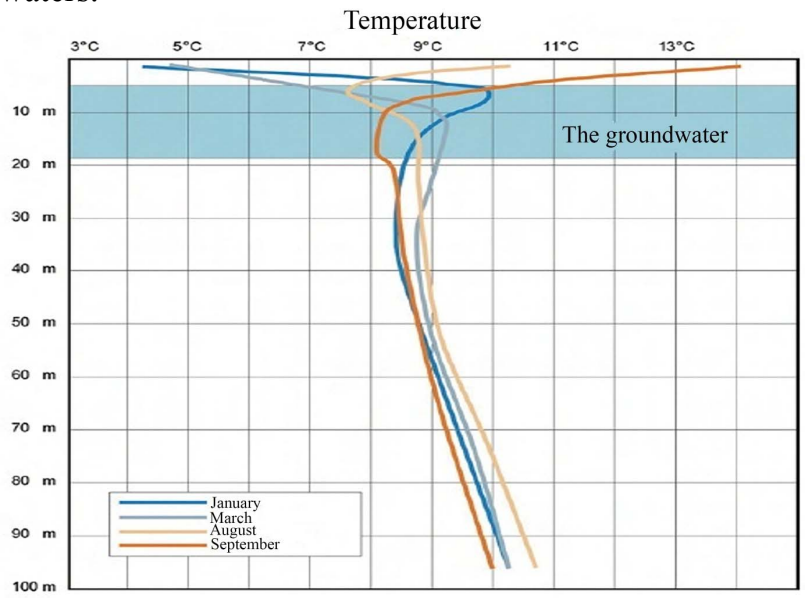

Figure 2. Seasonal (annual) fluctuations of temperature changes in the geological environment

In the use of layered model of the geological environment, it is necessary to supplement it with the dependencies of generalized environmental parameters conductivity and dielectric permeability on the temperature.

As it is seen from the data of temperature control at the upper part of the geological section the temperature distribution in depth is well approximated by a piecewise linear function (Fig. 3):

$$
\begin{gathered}
T(h)=T_{0}+\frac{T_{m}-T_{0}}{h_{m}} h ; h=\left[0, h_{m}\right] ; \\
T(h)=\frac{T_{m} h_{c}+T_{c} h_{m}}{h_{m}-h_{c}}+\frac{T_{m}-T_{c}}{h_{m}-h_{c}} h ; h=\left[h_{m}, h_{c}\right] ; \\
T(h)=T_{c} ; h=\left[h_{c}, \infty\right] .
\end{gathered}
$$

In this case, for the used parametrical dependence of temperature in the geological section from depth it is supposed that data on $T_{c}$ are known for all points of local control, the information on $T_{0}$ is obtained as a result of straight lines, and on $T_{m}$ - of indirect measurements in points of local monitoring. In the assumption of finding of limit of karst inhomogeneity up to $h_{c}$ depth at compensation of temperature hindrances it is possible to use the method given in works $[16,17]$ for triplex 
parametrical geoelectric model. Wherein the upper layer $h=\left[0, h_{m}\right]$, described parameters $\sigma_{1}$ and $\varepsilon_{1}$, and lower layer $h=\left[h_{m}, h_{c}\right]$ with parameters $\sigma_{3}$ and $\varepsilon_{3}$, within which may be the heterogeneity of karst described complex parameter $\dot{\sigma}_{2}$.

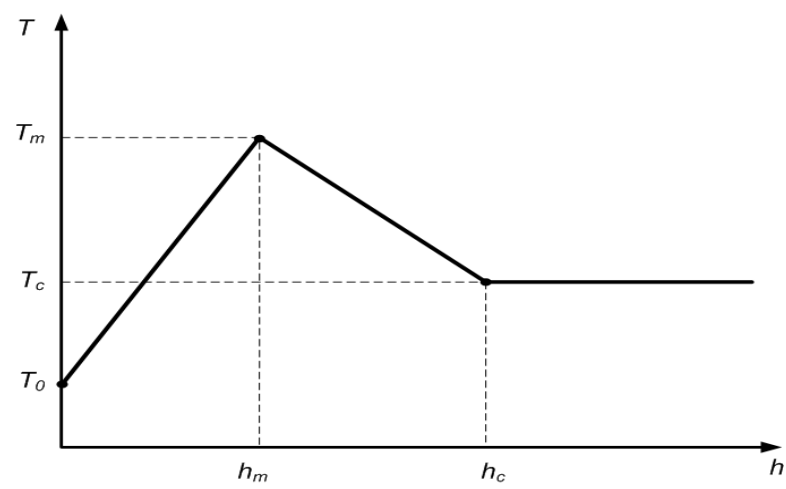

Figure 3. Parametrical model of distribution of temperature in a geological section

Complex conductivity of the controlled section of the medium on the basis of (1) and (2) can be expressed in the corresponding parametric model function:

$$
\begin{aligned}
& \sigma(j \omega, T)=\sigma_{1} \int_{0}^{h_{m}} \varsigma_{1}(h)\left(1-\alpha_{T \sigma 1}\left(T_{0}+\frac{T_{m}-T_{0}}{h_{m}} h\right)\right) \partial h+ \\
& +j \omega, \varepsilon_{1} \int_{0}^{h_{m}} \varsigma_{1}(h)\left(1-\alpha_{T \sigma 1}\left(T_{0}+\frac{T_{m}-T_{0}}{h_{m}} h\right)\right) \partial h+ \\
& \sigma_{3} \int_{h_{m}}^{h_{c}} \varsigma_{3}(h)\left(1-\alpha_{T \sigma 3}\left(\frac{T_{m} h_{c}+T_{c} h_{m}}{h_{m}-h_{c}}+\frac{T_{m}-T_{c}}{h_{m}-h_{c}} h\right)\right) \partial h+ \\
& \left.+j \omega, \varepsilon_{3} \int_{h_{,}}^{h_{c}} \varsigma_{3}(h)\left(1-\alpha_{T \varepsilon 3} \frac{T_{m} h_{c}+T_{c} h_{m}}{h_{m}-h_{c}}+\frac{T_{m}-T_{c}}{h_{m}-h_{c}} h\right)\right) \partial h+ \\
& +\left(\sigma_{2}\left(1-\alpha_{B \sigma} T_{B}\right)+j \omega \varepsilon_{2}\left(1-\alpha_{B \varepsilon} T_{B}\right)\right) \int_{h_{1}}^{h_{2}} \varsigma_{2}(h) \partial h
\end{aligned}
$$

where $h_{1}, h_{2}$ - is karst heterogeneity location area.

In the ratio (3) the following is unknown: the temperature coefficients an which can be defined on the basis of the regression analysis of the data of georadar monitoring and the data of monitoring of temperature under conditions of stationarity of temperature strains and taking into account geodynamic changes of karst inhomogeneity.

\section{AlgORITHM OF TEMPERATURE CORRECTION OF GEORADAR DATA}

The temperature correction algorithm is based on the fact that the total time of registration of the transfer coefficient of the environment for georadar sensing is divided into $\mathrm{N}$ geodynamically conditionally stable intervals (i.e. geodynamic changing of the transfer coefficient is fixed and is equal to $\left.\Delta H_{i}(\omega)\right)$. On the basis of (3) we have a linear regression relationship that combines the intervals of time, and allows to identify the geodynamic trend which can be formed as follows:

$$
H(\omega, T)=H\left(\omega, T_{0}\right)+\alpha_{T} T+\Delta H_{i}(\omega)
$$

where $i-$ is measurement interval, $\alpha_{T}-$ synthesis temperature coefficient.

For each time interval geodynamics of environment is completely determined by the variations of the transfer coefficient:

$$
\Delta_{i}=H\left(\omega, T_{0}\right)+\Delta H_{i}(\omega)
$$

Regression ratio is formed on the basis of the objective function:

$$
\psi(\omega, T)=\sum_{i=1}^{N} \sum_{j=1}^{M}\left(H_{i j}(\omega, T)-\alpha_{T} T_{i j}-\Delta_{i}\right)^{2}
$$

where $N$ - the number of intervals monitoring of geodynamic processes; $M$ - the number of measurement points in the control range.

As the result of the generalized temperature coefficient is defined as:

$$
\alpha_{T}=\frac{\sum_{i=1}^{N} \sum_{j=1}^{M} H_{i j}\left(T_{i j}-\frac{1}{M} \sum_{j=1}^{M} T_{i j}\right)}{\sum_{i=1}^{N} \sum_{j=1}^{M} T_{i j}\left(T_{i j}-\frac{1}{M} \sum_{j=1}^{M} T_{i j}\right)}
$$

The $\overline{H_{M}}=\frac{1}{M} \sum_{j=1}^{M} H_{i j}$, and $\overline{T_{M}}=\frac{1}{M} \sum_{j=1}^{M} T_{i j}$, we receive a calculated value of geodynamic variations of a transmission factor $\Delta_{i}$ taking into account temperature correction:

$$
\Delta_{i}=\overline{H_{M}}-\overline{T_{M}} \cdot \frac{\sum_{i=1}^{N} \sum_{j=1}^{M} H_{i j}\left(T_{i j}-\overline{T_{M}}\right)}{\sum_{i=1}^{N} \sum_{j=1}^{M} T_{i j}\left(T_{i j}-\overline{T_{M}}\right)}
$$

\section{Results of the Pilot Studies AND CONCLUSIONS}

Works on engineering geophysical inspection were performed on the platform of alleged construction of the Nizhny Novgorod NPP near the village of Monakovo in 
2010. During engineering and geophysical works 13 georadar profiles, by the common lengthiest $\sim 5305 \mathrm{~m}$ were passed. Works were performed at different times at different temperatures that was required by conditions of monitoring works as spring and in the fall. Profiles were carried out by the OKO-2 georadar, the antenna AB-90 block. The antenna block is screened and is constructed according to the scheme with an optical outcome, characteristics are provided in table 1.

TABLE I. CHARACTERISTICS OF THE USED ANTENNA

\begin{tabular}{|c|c|c|c|c|}
\hline $\begin{array}{c}\text { Antenna } \\
\text { assembly }\end{array}$ & $\begin{array}{c}\text { Central } \\
\text { frequency, } \\
\text { (MHz) }\end{array}$ & $\begin{array}{c}\text { Pulse } \\
\text { amplitude of } \\
\text { the } \\
\text { transmitting } \\
\text { antenna (B) }\end{array}$ & $\begin{array}{c}\text { The maximum } \\
\text { probing } \\
\text { depth, (m) }\end{array}$ & $\begin{array}{c}\text { The } \\
\text { resolution } \\
\text { of the } \\
\text { depth, } \\
\text { (m) }\end{array}$ \\
\hline $\mathrm{AB}-90$ & 90 & 700 & 16,0 & 0,5 \\
\hline
\end{tabular}

As the result of processing and interpretation of results of sensing, it is revealed that upper layers (up to 0.5-2 meters) consist mainly of sand; the subsequent layers consist of loam or clay with sand layers. These results are confirmed by results of drilling. Also, due to existence of clay layers and layers with high moisture content the nonuniform attenuation of the probing signal at depths of four - ten meters is revealed, that could be interpreted as manifestation of development of karst processes. However, the application of algorithms of temperature correction in compliance with ratios (3-7) allowed to eliminate the received ambiguity of the recorded data.

The said algorithm of temperature correction on the basis of parametric models of the test environment enables to formalize a preliminary stage of processing of the georadar sensing data at local levels of geodynamic control of karst processes, taking into account temperature variations in the geological section and separate the periodic temperature variations from geodynamic changes caused by karst processes.

\section{ACKNOWLEDGMENT}

This work was supported by a grant of the Ministry of Education and Science of the Russian Federation № 5.3606.2017/ PCH.

\section{REFERENCES}

[1] Y. Jiang, M. Liao, H. Wang, L. Zhang and T. Balz, "Deformation monitoring and analysis of the geological environment of pudong international airport with persistent scatterer SAR interferometry," Remote Sens., vol. 8, no. 12, 1021, 2016.

[2] Y. Qi, M. Fang and Z. Zheng, "Webgis-based system of "monitoring and preventing geological disaster rely on the masses," in Proceedings of the IEEE International Geoscience and Remote Sensing Symposium (IGARSS), 21-26 July 2013.

[3] C. R. Levine, R. D. Yanai, G. G. Lampman, D. A. Burns, C. T. Driscoll, G. B. Lawrence, J. A. Lynch and N. Schoch, "Evaluating the efficiency of environmental monitoring programs," Ecological Indicators, vol. 41, pp. 215, June 2014.
[4] A. A. Bykov, O. R. Kuzichkin and I. A. Kurilov, "Organization of electrolocation systems of geodynamic monitoring on the basis of the single-crystal microcomputer," Proceedings of the IEEE 8th International Conference on Intelligent Data Acquisition and Advanced Computing Systems: Technology and Applications (IDAACS'2015), 2015, pp. 582-586.

[5] R. V. Sharapov and O. R. Kuzichkin, "Geodynamic monitoring in area of nuclear power plant," Applied Mechanics and Materials, vol. 492, pp. 556-560, 2014.

[6] S. Cardimona, "Electrical resistivity techniques for subsurface investigation," in Proceedings of the 2nd International Conference on the Application of Geophysical and NDT Methodologies to Transportation Facilities and Infrastructure, Los Angeles, Calif., May 15-19, 2002.

[7] A. V. Tsaplev, O. R. Kuzichkin and R. V. Romanov, "Estimation of bias currents in the electrolocation monitoring system of the upper aquifer," in Proceedings of the 15th International Multidisciplinary Scientific GeoConference SGEM'2015, 2015, pp. 213-220.

[8] Yu. Kolokolov and A. Monovskaya, "Guess-work and reasonings on centennial evolution of surface air temperature in Russia. Part IV: Towards economic estimations of climate-related damages from the bifurcation analysis viewpoint?" Int. J. of Bifurcation and Chaos, vol. 26, no. 12, 1630033, 2016.

[9] Yu. Kolokolov and A. Monovskaya, "Multidimensional analysis of dynamics of annual warming-cooling cycles on the basis of index model of temperature observations," in Proceedings of the $8^{\text {th }}$ IEEE International Conference on Intelligent Data Acquisition and Advanced Computing Systems: Technology and Applications (IDAACS'2015), Warsaw, Poland, 24-26 September 2015, vol. 2, pp. 631-637.

[10] Yu. Kolokolov and A. Monovskaya, "Forecasting of vernal and autumnal margins in local climate dynamics," in Proceedings of the $8^{\text {th }}$ IEEE International Conference on Intelligent Data Acquisition and Advanced Computing Systems: Technology and Applications (IDAACS'2015), Warsaw, Poland, 24-26 September 2015, vol. 2, pp. 570-575.

[11] Edited by H. Di Benedetto, T. Doanh, H. Geoffrey and C. Sauzeat, Deformation Characteristics of Geomaterials, Departement Genie Civil et Batiment (DGCB. CNRS). Ecole Nationale des Travaux Publics de l'Etat, Vaulx-en-Velin. France.

[12] A. A. Bykov and O. R. Kuzichkin, "Spectral description of elementary geoelectric models of karst inhomogeneities," in Proceedings of the International Multidisciplinary Scientific GeoConference Surveying Geology and Mining Ecology Management, SGEM 3 (1), pp. 1005-1010.

[13] T. Yamasaki, K. Isono and T. Hinata, "Analysis of electromagnetic fields in inhomogeneous medium by Fourier series expansion methods," in Proceedings of the IEEE/ACES International Conference on Wireless Communications and Applied Computational Electromagnetics, 2005, pp. 917-920.

[14] G. Lange and K. Seidel, "Environmental Geology," Chapter "Electromagnetic Methods", Handbook of Field Methods and Case Studies, Springer Berlin Heidelberg New York, pp. 239-281.

[15] V. Radulescu, F. Radulescu, C. Diacopolos and M. Popescu, "Geoelectrical study for delineating underground cavities in karst areas," GeoEcoMarina, vol. 13, issue 1, p89, 2007.

[16] R. Sharapov and O. Kuzichkin, "Monitoring of karst-suffusion formation in area of nuclear power plant," in Proceedings of the 7th IEEE International Conference on Intelligent Data Acquisition and Advanced Computing Systems (IDAACS'2013), Berlin, Germany, 12-14 September 2013, vol. 2, pp. 810-813.

[17] A. A. Bykov and O. R. Kuzichkin, "Regression prediction algoritm of suffusion processes development during geoelectric monitoring," Advances in Environmental Biology, no. 8. pp. 1404$1410,2014$. 